\title{
High prevalence of cattle fascioliasis in coastal areas of Thua Thien Hue province, Vietnam
}

\author{
Nga Thi NGUYEN ${ }^{1,3)}$, Thinh Cong LE'), Minh Duc Co VO ${ }^{3)}$, Hoang VAN CAO ${ }^{3)}$, \\ Ly Thi NGUYEN ${ }^{3)}$, Khanh Thi HO3), Quyet Ngoc NGUYEN ${ }^{3)}$, Vui Quang TRAN ${ }^{3)}$ \\ and Yasunobu MATSUMOTO ${ }^{1) *}$
1)Laboratory of Global Animal Resource Science, Department of Global Agricultural Sciences, Graduate School of Agricultural and Life Sciences, The University of Tokyo, 1-1-1 Yayoi, Bunkyo-ku, Tokyo 113-8657, Japan
${ }^{2)}$ Department of Immunology and Vaccine, Institute of Biotechnology, Hue University, Phu Thuong Commune, Phu Vang district, Thua Thien Hue province, Vietnam
3)Laboratory of Parasitology, Department of Parasitology and Infectious disease, Graduate School of Agricultural and Forestry, Hue University, 24 Phung Hung street, Hue city, Vietnam

J. Vet. Med. Sci.

79(6): 1035-1042, 2017

doi: 10.1292/jvms.16-0331

Received: 25 June 2016 Accepted: 17 April 2017 Published online in J-STAGE:

1 May 2017

\begin{abstract}
In Vietnam, especially central Vietnam, patients with fascioliasis are increasingly being reported. Since the fascioliasis is zoonotic, survey on the cattle fascioliasis should be informative for the control of human fascioliasis. In this study, the prevalence of cattle fascioliasis as well as the density of the intermediate host snails, Lymnaea swinhoei and L. viridis, were studied in Thua Thien Hue (TTH) province during 2014-2015. A total of 572 cattle feces were examined from 27 communes in 9 districts. Fasciola eggs were detected in cattle from 24 communes with an average prevalence of $23.4 \%$ (134/572). The highest prevalence was detected in cattle in the coastal plain terrain $(31.0 \%)$ followed by plain $(25.5 \%)$, mountain $(21.7 \%)$, and low hilly $(16.2 \%)$ terrains. The highest proportion of heavy infection ( $>200$ EPG) was observed in the coastal plain terrain $(36.1 \%)$, followed by mountains $(20.0 \%)$, low hills $(13.0 \%)$, and plains $(8.9 \%)$. Low number of heavy infection, as well as relatively low prevalence in low hills and plains were associated with the extensive use of anti-fluke treatments. High number of intermediate host snails in low hilly and plain terrains also indicate high risk of fascioliasis. In this study, the density of Lymnaea snails in the coastal plain terrain was found to be very high $\left(17.3\right.$ snails $\left./ \mathrm{m}^{2}\right)$ compared to that in previous studies. This is the first report indicating the recent expansion of cattle fascioliasis in the coastal region in Vietnam.

KEY WORDS: cattle, fascioliasis, Lymnaea, Thua Thien Hue province, Vietnam
\end{abstract}

Human fascioliasis is emerging or re-emerging in many countries [58]. In Vietnam, the status of human fascioliasis has changed significantly in recent years; only 2 cases of human fascioliasis occurred in 1978 and 500 cases were reported from 1997 to 2000 [51]. However, the number of reported cases drastically increased recently: 3,838 (2006), 2,196 (2007), 2,000 (2008), 4,300 (2009) and 9,985 (2011) [52-54]. Importantly, 84.8-92.3\% of cases of human fascioliasis occurred in central Vietnam [52]. Humans may be infected with Fasciola parasites by eating aquatic plants, by drinking fresh untreated water contaminated with metacercariae of the Fasciola spp. [1, 2, 6], or by consuming dishes with raw liver from cattle infected with the juvenile flukes [48].

Cattle infected with Fasciola spp. may be responsible for human infection since the cattle-raising area is often in close proximity to the aquatic plants grown for human consumption $[6,13,17,26,34,47]$. The prevalence of cattle fascioliasis has been reported to be $22.0-23.5 \%$ in northern Vietnam [21] and 1.4-51.9\% in southern Vietnam [20, 34]. In central Vietnam, where the highest number of human cases has been reported, survey on cattle fascioliasis was restricted in south-central Vietnam [33, 35], and no recent survey focusing on central and north-central Vietnam, including the Thua Thien Hue (TTH) province, has been reported. Thus, in the present study, an investigation into the infection of liver flukes (Fasciola spp.) in cattle of the TTH province was conducted, and the distribution of snails, which are the intermediate hosts, was examined. The knowledge of fascioliasis in this province may aid in the improved understanding of the disease in central Vietnam.

\footnotetext{
*Correspondence to: Matsumoto, Y., Laboratory of Global Animal Resource Science, Department of Global Agricultural Sciences, Graduate School of Agricultural and Life Sciences, The University of Tokyo, 1-1-1 Yayoi, Bunkyo-ku, Tokyo 113-8657, Japan. e-mail: aymat@mail.ecc.u-tokyo.ac.jp

@2017 The Japanese Society of Veterinary Science
}

This is an open-access article distributed under the terms of the Creative Commons Attribution Non-Commercial No Derivatives (by-ncnd) License. (CC-BY-NC-ND 4.0: https://creativecommons.org/licenses/by-nc-nd/4.0/) 


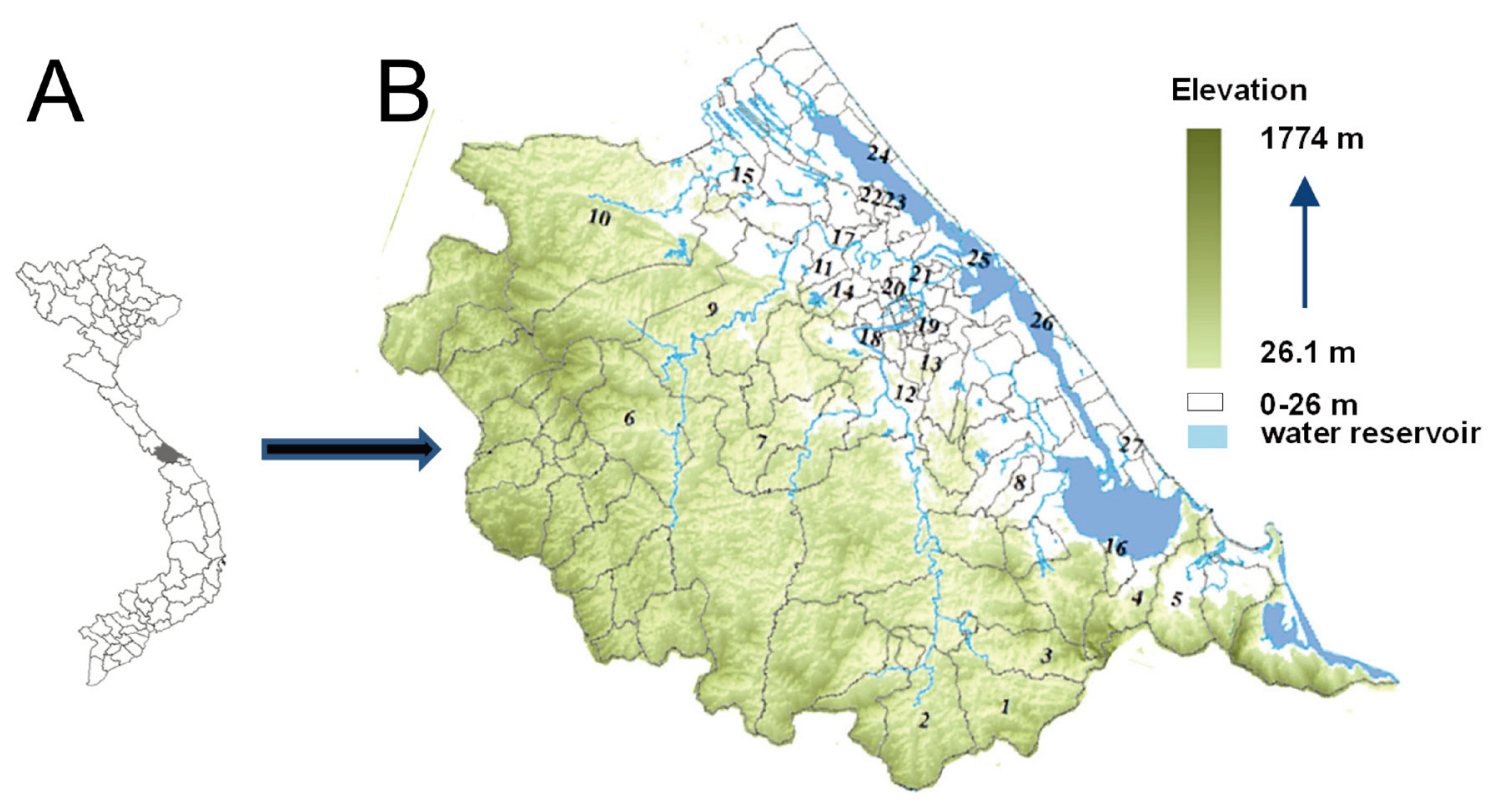

Fig. 1. A: Map of Vietnam. Thua Thien Hue (TTH) province is filled. B: Enlarged map of TTH province. Light blue color illustrated for water reservoir. Gradient green color represent altitude. Numbers indicated are communes where cattle feces and snails were sampled, which are corresponding to those indicated in Table 1.

Although fascioliasis is recognized in Vietnam, no national campaign for fascioliasis prevention has been established. In TTH province, cattle are treated for fascioliasis independently by owner's will or veterinarian's suggestion. Most of the fascioliasis surveillance were conducted by fecal examination for Fasciola eggs [20, 21, 33-35]. In order to file epidemiological data in TTH province, fecal egg counting was also applied in this study. Since individual medical treatment might affect the results of fecal examination, interview to cattle owners and veterinarians were conducted.

The species of the Lymnaeidae family are known as intermediate hosts for F. gigantica or $F$. hepatica $[3,27,35,43,46]$. In Vietnam, it has been reported that the most frequent intermediate hosts of F. gigantica are Lymnaea swinhoei and L. viridis [20, 35, $43,57]$. The habitat preference of snails is lowland plains with slow moving streams; generally, a high number of snails reside in this environment [8], resulting in the high prevalence of cattle fascioliasis [23, 24, 50]. Highlands and low hills with fast currents or coastal areas with higher salinity are considered unsuitable habitats for the snails [8,23, 57], resulting in a low prevalence of the disease $[20,50,57]$. Thus, areas in TTH were categorized as mountain, low hilly, plain, or coastal plain terrains and were analyzed separately.

\section{MATERIALS AND METHODS}

\section{Study area}

TTH is located in north-central Vietnam (16.0 to $16.5^{\circ}$ latitude and 107.0 to $108.8^{\circ}$ longitude), with an area of $5,053,990 \mathrm{~m}^{2}$, long and narrow land with an average width of $60 \mathrm{~km}$ and length of $127 \mathrm{~km}$ (Fig. 1A). TTH lies in the monsoon tropical area, which has a dry season that lasts from March to August and a rainy season from September to February.

TTH province involves 9 districts and 152 communes. There were 27 communes in 9 districts (Table 1) located near main rivers that were chosen as study areas and categorized into 4 topographic terrains by altitude; mountains $(250-1,774 \mathrm{~m})$, low hills $(30-250 \mathrm{~m})$, plains, and coastal plains $(0-30 \mathrm{~m})$ (Table 1). Coastal plain terrains were defined as plains areas facing the sea or lagoon (Fig. 1B).

\section{Cattle-fecal sample collection}

Fecal samples were collected from domestic yellow cattle and yellow crossbred with zebu raised in the study areas between April and October, 2014. Animals were selected randomly regardless of age or gender. In most of the communes, multiple smallholders shared pastures. In each commune, cattle were followed and feces were collected immediately after they dropped. Samples were collected one time in each commune to avoid double counting. More than 10 samples per commune were collected, except in Loc Tri and Binh Dien, where only 9 samples were collected due to low cattle numbers. For the sampled cattle, age was estimated by the owners' information and the number of horn growth rings (HGRs) [16, 29]. The sex of cattle was recorded but not separately analyzed. On each farm, about $10 \mathrm{~g}$ of fecal samples from each animal were collected using a polythene bag worn over the fingers. All samples were labeled and transported to the Parasitology Laboratory, Hue University for examination. 
Table 1. Study area, prevalence of cattle Fasciola spp. infection, and treatment

\begin{tabular}{|c|c|c|c|c|c|}
\hline Terrain & Commune & No. examined & No. infected & Prevalence $(\%)$ & Treatment $^{\text {a) }}$ \\
\hline \multirow{6}{*}{ Mountain terrain } & Thuong Lo (1) & 25 & 0 & 0.0 & $\mathrm{Ra}$ \\
\hline & Thuong Nhat (2) & 32 & 10 & 31.3 & - \\
\hline & Huong Loc (3) & 23 & 12 & 52.2 & - \\
\hline & Loc Tri (4) & 9 & 2 & 22.2 & $\mathrm{Ni}$ \\
\hline & Loc Thuy (5) & 22 & 4 & 18.2 & $\mathrm{Ra}$ \\
\hline & Hong Ha (6) & 27 & 2 & 7.4 & $\mathrm{Ni}$ \\
\hline \multicolumn{2}{|c|}{ Subtotal } & 138 & 30 & 21.7 & \\
\hline \multirow[t]{7}{*}{ Low hilly terrain } & Binh Dien (7) & 9 & 1 & 11.1 & $\mathrm{Ra}$ \\
\hline & Loc Son (8) & 19 & 1 & 5.3 & $\mathrm{Ni}$ \\
\hline & Phong Son (9) & 29 & 3 & 10.3 & $\mathrm{Tr}, \mathrm{Al}$ \\
\hline & Phong My (10) & 20 & 7 & 35.0 & - \\
\hline & Huong Van (11) & 15 & 9 & 60.0 & -b) \\
\hline & Thuy Bang (12) & 23 & 1 & 4.3 & $\mathrm{Ni}$ \\
\hline & Thuy Duong (13) & 27 & 1 & 3.7 & $\mathrm{Ni}$ \\
\hline \multicolumn{2}{|c|}{ Subtotal } & 142 & 23 & 16.2 & \\
\hline \multirow[t]{8}{*}{ Plain terrain } & Huong Chu (14) & 21 & 14 & 66.7 & $\mathrm{Ni} /-\mathrm{c})$ \\
\hline & Phong Dien town (15) & 20 & 1 & 5.0 & $\mathrm{Ni}$ \\
\hline & Phu Loc town (16) & 28 & 1 & 3.6 & $\operatorname{Tr}$ \\
\hline & Quang Phu (17) & 14 & 3 & 21.4 & $\mathrm{Bi}$ \\
\hline & Thuy Bieu (18) & 25 & 17 & 68.0 & - \\
\hline & Xuan Phu (19) & 21 & 4 & 19.0 & $\mathrm{Ni}$ \\
\hline & Huong So (20) & 18 & 5 & 27.8 & $\mathrm{Ni}$ \\
\hline & Phu Mau (21) & 29 & 0 & 0.0 & $\operatorname{Tr}$ \\
\hline \multicolumn{2}{|c|}{ Subtotal } & 176 & 45 & 25.6 & \\
\hline \multirow[t]{6}{*}{ Coastal plain terrain } & Sia town (22) & 10 & 5 & 50.0 & - \\
\hline & Quang Phuoc (23) & 13 & 5 & 38.5 & - \\
\hline & Quang Ngan (24) & 20 & 10 & 50.0 & - \\
\hline & Thuan An (25) & 26 & 4 & 15.4 & $\mathrm{Ni}$ \\
\hline & Phu Dien (26) & 24 & 0 & 0.0 & $\mathrm{Ni}$ \\
\hline & Vinh My (27) & 23 & 12 & 52.2 & - \\
\hline \multicolumn{2}{|c|}{ Subtotal } & 116 & 36 & 31.0 & \\
\hline \multicolumn{2}{|c|}{ Total } & 572 & 134 & 23.4 & \\
\hline
\end{tabular}

a) Abreviation of anti-fluke treatments are; Ra: Rafozanide, Ni: Nitroxynil, Tr: Triclabendazol, Al: Albendazol, Bi: Bithionol. b) Cattle were treated with Levamisol. c) Among 9 farms involved, cattle in 3 farms were treated with Nitroxynil and 6 farms with Levamisol.

\section{Fasciola spp. egg detection by fecal sedimentation}

Fasciola eggs were detected by the fecal sedimentation method [36]. Briefly, $5 \mathrm{~g}$ of cattle feces were re-suspended in $500 \mathrm{~m} l$ water and passed through a $250-\mu \mathrm{m}$ pore sieve colander. The retained material was washed thoroughly; the filtrate was transferred to a $500 \mathrm{ml}$ conical beaker that was allowed to stand for $30 \mathrm{~min}$; the supernatant was discarded. This step was repeated $3-5$ times, depending on the sample. After the supernatant was discarded, the remaining $12-15 \mathrm{~m} l$ was transferred to a $10 \mathrm{~cm}$ petri dish and a few drops of methylene blue were added. The sediment was applied to a slide, covered with a coverslip, and examined under a microscope at $100 \times$ magnification to view the eggs. The procedure was repeated until all sediment was examined. Identification of Fasciola eggs was performed using the standard parasitological keys as described by Hussein [22], Phalee [42] and Valero [55].

\section{Determination of eggs per gram (EPG) by the McMaster method}

The positive feces for Fasciola eggs obtained through the fecal sedimentation method were processed to count the EPG using the McMaster method [19, 49]. Two grams of feces were placed into a flask containing $60 \mathrm{~m} l$ of $\mathrm{ZnSO}_{4}$ saturated solution. While mixing vigorously a sample of the mixture was obtained with a pipette and transferred into one of the chambers of the McMaster slide. The procedure was repeated and the sample was put into another chamber. After $30 \mathrm{sec}$, the total number of eggs in the designated area of six chambers $(900 \mu l)$ were counted. The EPG was calculated by multiplying the number by $100 / 3$. The intensity of infection with Fasciola parasites was classified as light $(E P G \leq 100)$, moderate $(100<E P G \leq 200)$ and heavy $(200<E P G)$.

\section{Chemotherapy for cattle fascioliasis}

In each commune where cattle feces were sampled, farm owners and veterinarians working on their farms were interviewed for the use of parasitecidal medicines. 


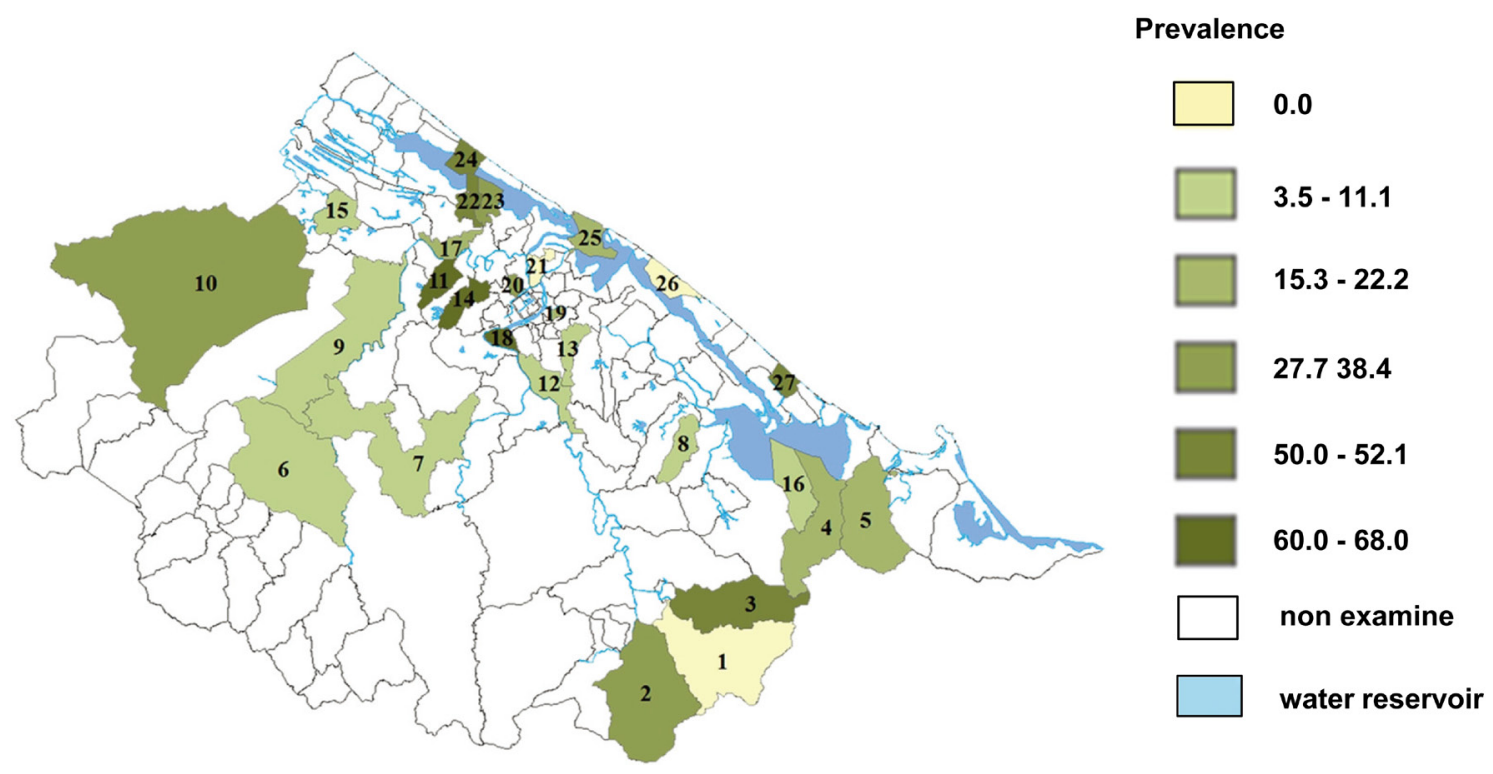

Fig. 2. Prevalence of Fasciola spp. of cattle in TTH province. Light blue color illustrated for water reservoir. Light yellow color indicate the commune where all cattle were negative for Fasciola spp. eggs. Gradient green color represent communes with cattle positive for Fasciola spp. eggs; intensity of color corresponding to the infectivity as indicated. White color indicates communes not examined. Numbers indicated are communes where cattle feces and snails were sampled, which are corresponding to those indicated in Table 1.

\section{Collection and identification of Lymnaea snails}

Lymnaea snails were collected and examined from November 2014 to October 2015. Snails less than 2 mm were not collected because species identification was difficult. Snail collection sites included irrigation canals, ponds, and paddy fields, which were located near cattle grazing areas. Snails were collected from at least 3 sites including each of above mentioned different habitats per commune. At each collection site, snails were collected from 5 locations. The average snail density $\left(\mathrm{snails} / \mathrm{m}^{2}\right)$ of each site was calculated from snail counts in 5 locations where at least one snail was found. A monthly average of snail density was calculated from sites in each terrain. At each sampling location, a 1- $\mathrm{m}^{2}$ frame was established; all snails on the surface and those attached to water plants were picked up by hand. Snails that were in deep area were collected using a $50 \mathrm{~cm}$ diameter mesh bag. The contents of each mesh bag were transferred to a $70 \mathrm{~cm}$ bamboo sieve. Lymnaea snails, including L. swinhoei and L. viridis, known intermediate hosts of F. gigantica, were collected. Samples were transported to the laboratory where Lymnaea snails were identified morphologically according to the standard protocol of Dang et al. [7], and the snails identified as L. swinhoei and L. viridis were counted. The snail were identified as juveniles and adults size base on the shell length, 2-4 mm and above $4 \mathrm{~mm}$ for Lymnaea viridis [28], 2-5 $\mathrm{mm}$ and above $5 \mathrm{~mm}$ for Lymnaea swinhoei [43], respectively.

\section{Topographic profile}

To assess the topographic profile, ArcGis software 10.3 (Eri, Redlands, CA, U.S.A.), and a Digital Elevation Model from ASTGM2-N16E107 dataset to ASTGTM2-N16E108 data aggregated to seconds, produced by the United States Geological Survey (USGS).

\section{Data management and statistical analysis}

The statistical analysis of data collected was reduced to contingency tables. Statistical Package for Social Science (SPSS), version 22.0 (SPSS Chicago Inc., Chicago, IL, U.S.A.) was used to determine Chi-square or Fisher's exact test where appropriate $P$ values were less than $0.05(P<0.05)$.

\section{RESULTS}

A total of 572 cattle fecal samples were collected. The prevalence of cattle fascioliasis varied within each terrain, as well as between terrains (Fig. 2 and Table 1). Cattle in 24 of 27 communes in the four terrains were found to be positive for Fasciola eggs. The highest and second highest prevalence rates were observed in the communes belonging to plain terrain- $68.0 \%$ in Thuy Bieu and $66.6 \%$ in Huong Chu - followed by $60.0 \%$ in Huong Van, a commune in low hilly terrain. Interestingly, the highest average prevalence of Fasciola spp. in the TTH province was found in the coastal plain (31.0\%), followed by plain (25.5\%), mountain $(21.7 \%)$, and low hilly $(16.2 \%)$ terrains.

The distribution of the severity of infection in the 572 cattle from all terrains examined was as follows: light, 10.5\% (60/572); 
Table 2. Fasciola spp. infection intensity in cattle of TTH province in association to the age and topography

\begin{tabular}{|c|c|c|c|c|c|c|c|c|c|c|c|c|c|}
\hline \multirow[b]{2}{*}{ Age $^{a)}$} & \multicolumn{3}{|c|}{ Mountain terrain } & \multicolumn{3}{|c|}{ Low hilly terrain } & \multicolumn{3}{|c|}{ Plain terrain } & \multicolumn{3}{|c|}{ Coastal plain terrain } & \multirow[b]{2}{*}{$\begin{array}{c}\text { Total }^{\mathrm{d})} \\
(\%)\end{array}$} \\
\hline & $\begin{array}{l}\text { Light }^{\text {b) }} \\
(\%)\end{array}$ & $\begin{array}{c}\text { Moderate } \\
(\%)\end{array}$ & $\begin{array}{c}\text { Heavy } \\
(\%)\end{array}$ & $\begin{array}{l}\text { Light } \\
(\%)\end{array}$ & $\begin{array}{c}\text { Moderate } \\
(\%)\end{array}$ & $\begin{array}{c}\text { Heavy } \\
(\%)\end{array}$ & $\begin{array}{l}\text { Light } \\
(\%)\end{array}$ & $\begin{array}{c}\text { Moderate } \\
(\%)\end{array}$ & $\begin{array}{c}\text { Heavy } \\
(\%)\end{array}$ & $\begin{array}{l}\text { Light } \\
(\%)\end{array}$ & $\begin{array}{c}\text { Moderate } \\
(\%)\end{array}$ & $\begin{array}{c}\text { Heavy } \\
(\%)\end{array}$ & \\
\hline$<1$ & $(-)$ & & & $\begin{array}{c}1 / 1 \\
(100.0)\end{array}$ & & & $\begin{array}{c}2 / 2 \\
(100.0)\end{array}$ & $\begin{array}{c}0 / 2 \\
(0.0)\end{array}$ & & $\begin{array}{c}2 / 2 \\
(100.0)\end{array}$ & $\begin{array}{c}0 / 2 \\
(0.0)\end{array}$ & $\begin{array}{c}0 / 2 \\
(0.0)\end{array}$ & $\begin{array}{c}5 / 30 \\
(16.7)\end{array}$ \\
\hline $1-3$ & $\begin{array}{c}6 / 12 \\
(50.0) \\
\end{array}$ & & $\begin{array}{c}2 / 12 \\
(16.7)\end{array}$ & $\begin{array}{c}7 / 8 \\
(87.5) \\
\end{array}$ & $\begin{array}{c}1 / 8 \\
(12.5) \\
\end{array}$ & & & & & $\begin{array}{c}5 / 15 \\
(33.3) \\
\end{array}$ & & & \\
\hline$>3-5$ & $\begin{array}{c}5 / 9 \\
(55.6)\end{array}$ & $\begin{array}{c}3 / 9 \\
(33.3)\end{array}$ & $\begin{array}{c}1 / 9 \\
(11.1)\end{array}$ & $\begin{array}{c}2 / 6 \\
(33.3)\end{array}$ & $\begin{array}{c}3 / 6 \\
(50.0)\end{array}$ & $\begin{array}{c}1 / 6 \\
(16.7)\end{array}$ & $\begin{array}{c}1 / 9 \\
(11.1)\end{array}$ & $\begin{array}{c}6 / 9 \\
(66.7)\end{array}$ & $\begin{array}{c}2 / 9 \\
(22.2)\end{array}$ & $\begin{array}{c}3 / 13 \\
(23.0)\end{array}$ & $\begin{array}{c}6 / 13 \\
(46.2)\end{array}$ & $\begin{array}{c}4 / 13 \\
(30.8)\end{array}$ & $\begin{array}{c}37 / 150 \\
(24.7)\end{array}$ \\
\hline$>5$ & $\begin{array}{c}5 / 9 \\
(55.6)\end{array}$ & $\begin{array}{c}1 / 9 \\
(11.1)\end{array}$ & $\begin{array}{c}3 / 9 \\
(33.3)\end{array}$ & $\begin{array}{c}2 / 8 \\
(25.0)\end{array}$ & $\begin{array}{c}4 / 8 \\
(50.0)\end{array}$ & $\begin{array}{c}2 / 8 \\
(25.0)\end{array}$ & $\begin{array}{c}1 / 5 \\
(20.0)\end{array}$ & $\begin{array}{c}3 / 5 \\
(60.0)\end{array}$ & $\begin{array}{c}1 / 5 \\
(20.0)\end{array}$ & $\begin{array}{c}3 / 6 \\
(50.0)\end{array}$ & $\begin{array}{c}1 / 6 \\
(16.7)\end{array}$ & $\begin{array}{c}2 / 6 \\
(33.3)\end{array}$ & $\begin{array}{c}28 / 125 \\
(22.4)\end{array}$ \\
\hline Total & $\begin{array}{l}16 / 30 \\
(53.3)\end{array}$ & $\begin{array}{c}8 / 30 \\
(26.7)\end{array}$ & $\begin{array}{c}6 / 30 \\
(20.0)\end{array}$ & $\begin{array}{l}12 / 23 \\
(52.2)\end{array}$ & $\begin{array}{c}8 / 23 \\
(34.8)\end{array}$ & $\begin{array}{c}3 / 23 \\
(13.0)\end{array}$ & $\begin{array}{l}22 / 45 \\
(48.9)\end{array}$ & $\begin{array}{l}19 / 45 \\
(42.2)\end{array}$ & $\begin{array}{l}4 / 45 \\
(8.9)\end{array}$ & $\begin{array}{c}13 / 36 \\
(36.1)\end{array}$ & $\begin{array}{l}12 / 36 \\
(33.3)\end{array}$ & $\begin{array}{l}11 / 36 \\
(30.6)\end{array}$ & $\begin{array}{c}134 / 572 \\
(23.4)\end{array}$ \\
\hline
\end{tabular}

a) Ages were estimated by owners' information and the number of horn growth rings (HGRs) [16, 29]. b) The intensity of infection with Fasciola parasites was classified as light $(\mathrm{EPG}<100)$, moderate $(100<\mathrm{EPG}<200)$ and heavy $(200<\mathrm{EPG})$. c) Infection intensity presented as numbers of infected cattle in each category /total number of cattle infected in each terrain (percentage). d) Total infection intensity presented as numbers of infected cattle in each age category /total number of cattle in each age category (percentage).

moderate, $8.4 \%$ (24/572); and high, 4.5\% (26/572). Cattle with the fluke eggs in each terrain were listed according to the severity of infection and age group (Table 2). The highest proportion of high severity of infection was detected in the coastal plain (36.1\%), followed by mountain $(20.0 \%)$, low hilly $(13.0 \%)$, and plain $(8.9 \%)$ terrains. Although fecal examinations for cattle less than 1 year were limited, the fluke eggs were found in $16.3 \%(5 / 30)$ of cattle less than 1 year, which was slightly lower than cattle in other categories, and all of them were light infections (Table 2). No significant difference of infectivity was observed between cattle aged 1 year and older.

As for the control of fascioliasis, rafozanide, nitroxynil, triclavendazol, alvendazol coupled with triclavendazol, and bithionol were used (Table 1). In this study, 60.1, 75.4, 75.6 and $43.1 \%$ of examined cattle in mountain, low hilly, plain and coastal plain terrains, respectively, were from farms using anti-fluke chemicals (Table 3). Cattle in farms located in the same commune were treated as the same way, except for Huong Chu, where 3 out of 9 farms used nitroxynil. All infected cattle in Huong Chu were from farms without anti-liver fluke treatment. In some farm, levamizol was treated. The effect of anti-fluke treatment on cattle fascioliasis prevalence was shown in Table 3. In all terrains, anti-fluke-treated cattle showed lower prevalence (6.5-10.5\%) compared to non-treated cattle (40.0-72.1\%). The fascioliasis prevalence of non-used cattle in the plain terrain (72.1\%) was higher than those in other terrains (40.0-48.5\%) (Table 3). Average EPG of positive cattle were not different between different terrains, as well as between anti-fluke-treated and non-treated cattle (Table 3).

The monthly density of L. swinhoei and L. viridis was studied in four topographies from September 2014 to October 2015 in Thua Thien Hue province (Fig. 3). A total of 43,507 snails were collected during this period. Snails were collected from each terrain; mountain terrain, 170; low hilly terrain, 14,128; plain terrain, 24,053; and coastal plain terrain, 5,156. In mountain terrains, where the velocity of streams is high, snails were found only in 2 months; April and September. They were most commonly observed in paddy fields and small canals of irrigation systems year-round in low hilly, plain, and coastal plain terrains, exceptions included the month of October in low hilly terrain and December, May, and July in coastal plain terrain. Seasonal changes of the snail density in the low hilly, plain, and coastal plain terrains were similar. The snail decline in December may have been due to floods after the peak of rain in November. In January, small size snails increased. The snail density again declined in March. At the middle and end of the dry season, in August in low hilly terrain and October in plain terrain, snail density increased (Fig. 3).

\section{DISCUSSION}

In Vietnam, fascioliasis is most endemic in low hilly or plain terrains, respectively [13, 14, 32, 44, 57]. In this study, the prevalence of Fasciola parasite in low hilly and plain terrains were 16.2 and $25.6 \%$, respectively, which were relatively lower compared with previous researches in which those in low hilly and plain terrains were between 28.0 and $76.0 \%$ [32]. In addition, EPG of Fasciola eggs-positive feces was also relatively lower in low hilly and plain terrains (Table 2). One of the possible 


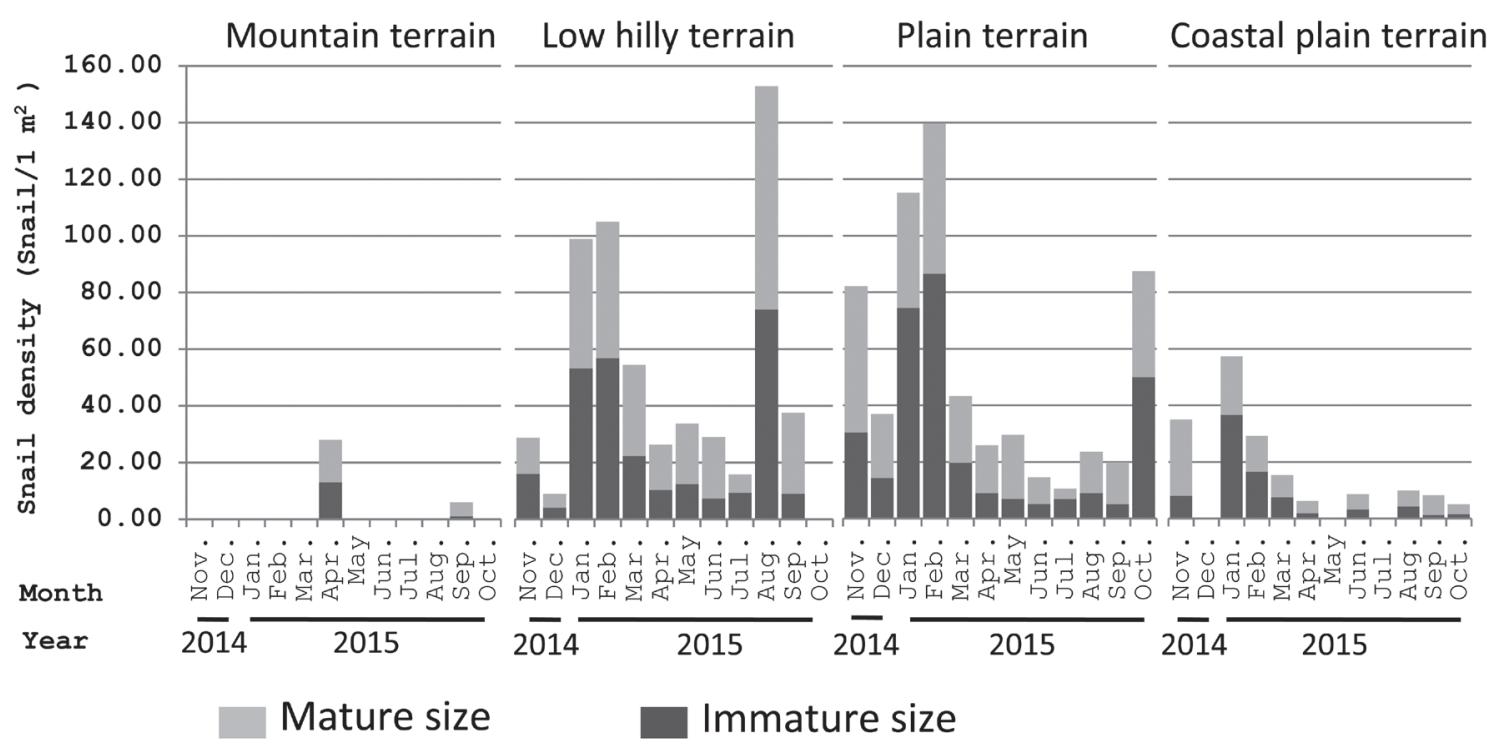

Fig. 3. Monthly density of the intermediate hosts of Fasciola spp. Only Lymnaea swinhoei and L. viridis, known intermediate hosts of F. gigantica, were identified morphologically according to the standard protocol of Dang et al. [7] and collected. Snails were separately counted for mature and immature sizes as indicated. Average density of snails in each terrain are calculated and presented as snail per $\mathrm{m}^{2}$.

reason for the decrease in number of heavy infection in low hilly and plain terrains is deworming treatments for cattle, since the prevalence of fascioliasis in untreated cattle in low hilly and plain terrains was comparable or rather higher $(72.1 \%$ in plain terrain) than other terrains (Table 3). The number of the intermediate host snails collected in this study was also high in plain terrain, followed by low hilly terrain, indicating the high risk of Fasciola infection in these areas. It was also notable to find high prevalence of fascioliasis in non-treated cattle from mountain terrain (Table 3), though snail density was very low.

There might be possible reasons for the seasonal change in snail density; the declination of snail density in December may have been due to the increasing water surface in rainy season plus with floods after the peak of rain in November. An increasing number of juvenile size snails observed indicated the hatching of new generations in January and February in low hilly, plain and coastal plain terrain. The snail density again declined in March to April, which may be due to the pesticides, such as dichlorvos, dinotefuran, and isoprocarb for preventing brown plant hopper (Nilaparvata lugens) and rice stem borers and herbicides, such as fenoxaprop-P-ethyl, diquat, paraquat, and ethoxylsulfuron, for preventing weed in paddy field, since some of these pesticides and herbicides were reported to affect snail productivity and mortality $[5,15,56]$. The importance of these environmental pesticides used for paddy field on intermediate host Lymnaea snails should be studied in the future. Small floods in April may also contribute to the decrease of the snail density. At the middle and end of the dry season, in August in low hilly terrain and October in plain terrain, snail density increased possibly due to the reduction of water and enrichment of snails (Fig. 3).

The high rate of heavy infection in coastal plain terrain (36.1\%, Table 2) may indicate the recent expansion of infection in coastal plain terrain. Several risk factors may explain the high prevalence of fascioliasis in the coastal plains of TTH province, Vietnam; the expansion of dams for blocking brackish water entry to the field for agricultural production and irrigation systems for supplying fresh water [9-12, 18, 30, 31,37-41], leading to the enlargement of field for cultivation and cattle raising, may enlarge the habitable area for intermediate host snails [4, 45], as is shown in bilharziasis [25], and enhance snail migration and/or the presence of Fasciola parasite eggs. Floods during the rainy season may also contribute to the dissemination of snails and Fasciola eggs to the coastal terrain. The increase of number of cattle introduced, both infected and uninfected with Fasciola spp., may also contribute to the high prevalence of fascioliasis. Overall, these factors lead to an increased distribution of the intermediate host to coastal areas. In this study, the density of the intermediate host snail of Fasciola spp. in coastal plains was high $\left(17.3 \mathrm{snails} / \mathrm{m}^{2}\right)$, varying from $0-57.4$ snails $/ \mathrm{m}^{2}$. This contrasts with results of previous studies, in which the density of the intermediate host in coastal areas was low [57]. For the control of fascioliasis in the coastal terrain, further surveys and studies on intermediate host snails including their infectivity of Fasciola larvae may be required.

In the present study, the use of anti-flukes were also surveyed in addition to the general fecal egg examination. It is true that EPG counting for all cattle is important for the comparison to the regional data from other province in Vietnam or from other countries. Knowing the use of medical treatment would provide additional information to control the disease.

CONFLICT OF INTEREST. None declared.

ACKNOWLEDGMENTS. The authors would like to thank Dr. Tran Anh Chau in the Department of Veterinary Medicine, TTH province for geographic and recent animal production data and guidance using Arcmap software. This research was supported 
(in part) through the Leading Graduates Schools Program, "Global Leader Program for Social Design and Management”, and the Japanese Ministry of Education, Culture, Sports, Science, and Technology. This work was also supported in part by a Grant-in-Aid for Scientific Research (B) from MEXTKAKENHI (Grant Number 24380164).

\section{REFERENCES}

1. Ashrafi, K. and Rezaeian, M. 2006. Potential transmission of human fascioliasis through traditional local foods, in Northern Iran. Iran. J. Public Health 35: 57-63.

2. Ashrafi, K., Valero, M. A., Massoud, J., Sobhani, A., Solaymani-Mohammadi, S., Conde, P., Khoubbane, M., Bargues, M. D. and Mas-Coma, S. 2006. Plant-borne human contamination by fascioliasis. Am. J. Trop. Med. Hyg. 75: 295-302. [Medline]

3. Berghen, P. 1964. Some Lymnaeidae as intermediate hosts of Fasciola hepatica in Belgium. Exp. Parasitol. 15: 118-124. [Medline] [CrossRef]

4. Bergkamp, G., McCartney, M., Dugan, P. and McNeely, J. 2000. Dams, Ecosystem Functions and environmental restoration thematic review II. 1 prepared as an input to the world commission on dams, Cape Town. Dams, Ecosystem Functions, and Environmental Restoration.http://www. globalrestorationnetwork.org/uploads/files/LiteratureAttachments/83_dams-ecosystem-functions-and-environmental-restoration.pdf [accessed June $25,2016]$.

5. Bhide, M., Gupta, P., Khan, A., Dubey, U., Thakur, P., Nema, P. and Jain, S. 2006. Morphological and biochemical studies on the different developmental stages of a fresh water snail, Lymnaea stagnalis (Lymnaeidae) after treatment with some pesticides. J. Environ. Biol. 27 Suppl: 359-366. [Medline]

6. Chen, J. X., Chen, M. X., Ai, L., Xu, X. N., Jiao, J. M., Zhu, T. J., Su, H. Y., Zang, W., Luo, J. J., Guo, Y. H., Lv, S. and Zhou, X. N. 2013. An outbreak of human fascioliasis in Southwest China. PLoS One 8: e71520. [Medline] [CrossRef]

7. Dang, T. N., Tran, B. T. and Pham, M. V. 1980. Identification of invertebrate in northern Vietnam. Sci. Tech. Publish. House, Hanoi, Vietnam, 481-490 (in Vietnamese).

8. de Kock, K. N., Wolmarans, C. T. and Bornman, M. 2003. Distribution and habitats of the snail Lymnaea truncatula, intermediate host of the liver fluke Fasciola hepatica, in South Africa. J. S. Afr. Vet. Assoc. 74: 117-122. [Medline] [CrossRef]

9. Department of Veterinary, T. T. H. province. 2013. Summarization of animal production, veterinary medicine and aquaculture in Thua Thien Hue Province in 2012 (in Vietnamese).

10. Department of Veterinary, T. T. H. province. 2013. Summarization of animal production, veterinary medicine and aquaculture in Thua Thien Hue Province in 2013 (in Vietnamese).

11. Department of Veterinary, T. T. H. province. 2014. Summarization of animal production, veterinary medicine and aquaculture in Thua Thien Hue Province in 2014 (in Vietnamese).

12. Department of Veterinary, T. T. H. province. 2015. Summarization of animal production, veterinary medicine and aquaculture in Thua Thien Hue Province in 2015 (in Vietnamese).

13. Do, N. D., Pham, L. V., Pham, D. N., Nguyen, H. V. and Nguyen, M. T. 2006. Animal raising practice and liver fluke prevalence in cattle in the Daklak province. J. Vet. Sci. Tech. 5: 68-72 (in Vietnamese).

14. Doan, P. V., Vuong, C. D. and Duong, H. T. 1995. Study on prevalence of fascioliasis in cattle in Hanoi and treatment application. J. Sci. Tech. Econ. Ma. Hanoi 1: 36-37 (in Vietnamese).

15. Ducrot, V., Pe'ry, A. R. R. and Lagadic, L. 2010. Modelling effects of diquat under realistic exposure patterns of the gastropod Lymneae stagnalis. Phil. Trans. R. Soc. B. 365: 3485-3494. [Medline] [CrossRef]

16. FAO 1993. Selection of cattle for work. http://www.fao.org/waicent/FAOINFO/agricult/aga/agap/frg/Draught/chap121/chap121.pdf [accessed June $25,2016]$.

17. Fica, A., Dabanch, J., Farias, C., Castro, M., Jercic, M. I. and Weitzel, T. 2012. Acute fascioliasis--clinical and epidemiological features of four patients in Chile. Clin. Microbiol. Infect. 18: 91-96. [Medline] [CrossRef]

18. General statistic office of Thua Thien Hue province. 2016. Total herd of animal in Thua Thien Hue province from 2008-2015.

19. Gibbons, L., Jacobs, D., Fox, M. and Hansen, J. 2014. Fecal examination of farm animals for helminth parasites. FAO. http://www.rvc.ac.uk/review/ Parasitology/Index/Index.htm [accessed June 25, 2016].

20. Ho, T. T. and Nguyen, P. N. 1987. Result of investigation on fascioliasis incidence in cattle- prevention and treatment measure. J. Agri. Sci. Tech. 2: 85-88 (in Vietnamese).

21. Holland, W. G., Luong, T. T., Nguyen, L. A., Do, T. T. and Vercruysse, J. 2000. The epidemiology of nematode and fluke infections in cattle in the Red River Delta in Vietnam. Vet. Parasitol. 93: 141-147. [Medline] [CrossRef]

22. Hussein, A.N. A., Hassan, I. M. and Khalifa, R. M. A. 2010. Description of eggs and larval stages of Fasciola, light and scanning electron microscopic studies. Re. J. Parasitol. 5: 1-12. [CrossRef]

23. Khatun, M. S., Asaduzzaman, M., Pallad, M. S. and Chakraborty, P. 2015. Risk factor analysis of fascioliasis in two geo-climatic regions of Bangladesh. Int. J. Sci. Re 4: 41-43.

24. Kuchai, J. A., Chishti, M. Z., Zaki, M. M., Rasool, S. A. D. M., Ahmad, J. and Tak, H. 2011. Some epidemiological aspects of fascioliasis among cattle of Ladakh. Glob. Vet. 7: 342-346.

25. Lanoix, J. N. 1958. Relation between irrigation engineering and bilharziasis. Bull. World Health Organ. 18: 1011-1035. [Medline]

26. Le, T. H., De, N. V., Agatsuma, T., Blair, D., Vercruysse, J., Dorny, P., Nguyen, T. G. and McManus, D. P. 2007. Molecular confirmation that Fasciola gigantica can undertake aberrant migrations in human hosts. J. Clin. Microbiol. 45: 648-650. [Medline] [CrossRef]

27. Lee, C. G., Cho, S. H. and Lee, C. Y. 1995. Metacercarial production of Lymnaea viridis experimentally infected with Fasciola hepatica. Vet. Parasitol. 58: 313-318. [Medline] [CrossRef]

28. Lloyd, J., Boray, J., Campbell, N. 2007. Identifying liver fluke snails. New South Wales Dept. Primary Industries Primefacts 476.

29. Mwanza, M., Nombulelo, M. F., Ngoma, M. and Mefane, M. 2013. Preliminary study on the validation of a traditional method of estimating parity in cow using horns growth rings. Life Sci. J. 10: 142-147.

30. Nguyen, C. V. 2011. Thua Thien Hue -Efforts for economic and social development. Hue city, Vietnam. http://dl.ueb.vnu.edu.vn/ bitstream/1247/9806/1/Thua thien Hue nhung no luc_Nguyen Van Cao.pdf (in Vietnamese) [accessed June 25, 2016].

31. Nguyen, C. V. 2011. The managements, operations and the implementation of tasks socio-economic, defense and security In Thua Thien Hue Province, period 2004-2011 (in Vietnamese).

32. Nguyen, T. G., Van De, N., Vercruysse, J., Dorny, P. and Le, T. H. 2009. Genotypic characterization and species identification of Fasciola spp. with 
implications regarding the isolates infecting goats in Vietnam. Exp. Parasitol. 123: 354-361. [Medline] [CrossRef]

33. Nguyen, T. G., Le, T. H., Dao, T. H. T., Tran, T. L., Praet, N., Speybroeck, N., Vercruysse, J. and Dorny, P. 2011. Bovine fasciolosis in the human fasciolosis hyperendemic Binh Dinh province in Central Vietnam. Acta Trop. 117: 19-22. [Medline] [CrossRef]

34. Nguyen, H. H. 2011. A study on fascioliasis of cattle in some provinces in Mekong delta and experiments on antihelminthic medication. J. Vet. Sci. Tech. 18: $26-35$ (in Vietnamese).

35. Nguyen, S. T., Nguyen, D. T., Van Nguyen, T., Huynh, V. V., Le, D. Q., Fukuda, Y. and Nakai, Y. 2012. Prevalence of Fasciola in cattle and of its intermediate host Lymnaea snails in central Vietnam. Trop. Anim. Health Prod. 44: 1847-1853. [Medline] [CrossRef]

36. Palmer, D. and Lyon, J. 2013. Detection of Trematode eggs and Eimerialeuckarti-Sedimentation method (FEST)-Feacal samples. DAFWA PAM 26: $1-10$.

37. People's community of Phu Loc district. 2013. On implementation of the socio-economic in 2013 and 2014 plan. Phu Loc, Thua Thien Hue.

38. People's community of Phu Loc district. 2014. On implementation of the socio-economic in 2014 and 2015 plan. Phu Loc, Thua Thien Hue.

39. People's community of Phu Loc district. 2015. On implementation of the socio-economic in 2015 and 2016 plan. Phu Loc, Thua Thien Hue.

40. People's community of Phu Loc district. 2013. On implementation of the socio-economic in 2013 and 2014 plan. Quang Dien, Thua Thien Hue.

41. People's community of Phu Loc district. 2014. On implementation of the socio-economic in 2014 and 2015 plan. Quang Dien, Thua Thien Hue.

42. Phalee, A., Wongsawad, C., Rojanapaibul, A. and Chai, J. Y. 2015. Experimental life history and biological characteristics of Fasciola gigantica (Digenea: Fasciolidae). Korean J. Parasitol. 53: 59-64. [Medline] [CrossRef]

43. Pham, D. N., Hoang, H. V., Nguyen, D. V. and Dang, T. C. T. 2012. New data on intermediate host of Fasciola in Vietnam. J. Biol. 34: 139-144 (in Vietnamese).

44. Phan, L. D. 1985. Study on biological characteristics of Fasciola gigantica and cattle fasciolosis in North Vietnam. J. Agri. Sci. Tech. 12: 675-678 (in Vietnamese).

45. Phan, H. T. and Dien, M. D. L. 2012. Upgrading and developing sea dyke, river coastal line erosion prevention system to response with climate change in Thua Thien Hue province (in Vietnamese).

46. Rondelaud, D., Vignoles, P., Abrous, M. and Dreyfuss, G. 2001. The definitive and intermediate hosts of Fasciola hepatica in the natural watercress beds in central France. Parasitol. Res. 87: 475-478. [Medline] [CrossRef]

47. Saba, R., Korkmaz, M., Inan, D., Mamikoğlu, L., Turhan, O., Günseren, F., Cevikol, C. and Kabaalioğlu, A. 2004. Human fascioliasis. Clin. Microbiol. Infect. 10: 385-387. [Medline] [CrossRef]

48. Taira, N., Yoshifuji, H. and Boray, J. C. 1997. Zoonotic potential of infection with Fasciola spp. by consumption of freshly prepared raw liver containing immature flukes. Int. J. Parasitol. 27: 775-779. [Medline] [CrossRef]

49. Taylor, M. A., Coop, R. L. and Wall, R. L. 2015. 4. Laboratory diagnosis of parasitism. In: Veterinary parasitology, 4th ed., Willy-Blackwell, New Jersey.

50. Tembely, S., Galvin, T. J., Craig, T. M. and Traore, S. 1988. Liver fluke infections of cattle in Mali. An abattoir survey on prevalence and geographic distribution. Trop. Anim. Health Prod. 20: 117-121. [Medline] [CrossRef]

51. Tran, V. H., Tran, T. K., Nguye, H. C., Pham, H. D. and Pham, T. H. 2001. Fascioliasis in Vietnam. Southeast Asian J. Trop. Med. Public Health 32 Suppl 2: 48-50. [Medline]

52. Trieu, T. N. 2009. Results Disease Prevention and liver fluke parasite helminth diseases in the central region Highlands first 6 months of 2009. Qui Nhon. http://www.impe-qn.org.vn/impe-qn/vn/portal/InfoPreview.jsp?ID=2873 (in Vietnamese) [accessed June 25, 2016].

53. Trieu, T. N. and Nguyen, C. V. 2011. Fascioliasis and re-emerging parasitic need to be addressed. http://www.impe-qn.org.vn/impe-qn/vn/portal/ InfoDetail.jsp?area $=58 \& c a t=1174 \& I D=4456$ (in Vietnamese) [accessed June 25, 2016].

54. Trieu, T. N. and Van Nguyen, C. 2012. Raising number of human fascioliasis cases in 2011 and demand for disease prevention at the community. Qui Nhon. http://www.impe-qn.org.vn/impe-qn/vn/portal/InfoDetail.jsp?area=58\&cat=1174\&ID=5629 (in Vietnamese) [accessed June 25, 2016].

55. Valero, M. A., Perez-Crespo, I., Periago, M. V., Khoubbane, M. and Mas-Coma, S. 2009. Fluke egg characteristics for the diagnosis of human and animal fascioliasis by Fasciola hepatica and F. gigantica. Acta Trop. 111: 150-159. [Medline] [CrossRef]

56. Vijaya, K. K. and Sowjanya, P. A. 2013. Histopathological effect of paraquat (Gramoxone) on the digestive gland of freshwater snail Lymnaea luteola (Lamarck: 1799) (Mollusca: Gastropoda). Int. J. Sci. Re. Environ. Sci. 1: 224-230.

57. Vu, N. S., Do, M. T., Nguyen, T. T. and Nguyen, H. S. 1989. Epizootiologic characteristics and control of fluke of Fasciola cattle and buffaloes in Phu Khanh and Daklak provinces. J. Agri. Sci. Tech. 5: 291-294 (in Vietnamese).

58. WHO, 2006. Informal Meeting on Use of Triclabendazole in Fascioliasis Control, report, 4-6. 